\title{
Copolymer based on lauryl methacrylate and poly(ethylene glycol) methyl ether methacrylate as amphiphilic macrosurfactant: Synthesis, characterization and their application as dispersing agent for carbon nanotubes
}

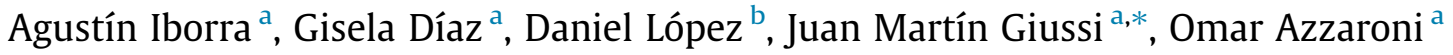 \\ ${ }^{a}$ Instituto de Investigaciones Fisicoquímicas Teóricas y Aplicadas (INIFTA), Departamento de Química, Facultad de Ciencias Exactas, Universidad Nacional de \\ La Plata, CONICET, 1900 La Plata, Argentina \\ ${ }^{\mathrm{b}}$ Instituto de Ciencia y Tecnología de Polímeros - CSIC, 28006 Madrid, Spain
}

\section{A R T I C L E I N F O}

\section{Article history:}

Received 27 July 2016

Received in revised form 12 December 2016

Accepted 17 December 2016

Available online 24 December 2016

\begin{abstract}
A B S T R A C T
The use of amphiphilic macrosurfactants as emulsifying agents has shown to have higher efficiency than that of low molecular weight surfactants. Compared to traditional surfactants, polymeric surfactants have lower critical micelle concentrations and lower diffusion coefficients. In this paper, we present a well defined copolymer based on lauryl methacrylate and poly(ethylene glycol) methyl ether methacrylate, prepared by solution radical copolymerization. The product was characterized by NMR and FTIR spectroscopies and the weight-average molecular weight and polydispersity index were analyzed by SEC. The thermal transitions and decomposition temperatures of the copolymers were determined by DSC and TGA, respectively. Due to the hydrophobic and hydrophilic nature of the monomer units, emulsification studies were performed. DLS experiments showed different sizes of the formed micelles depending on solvent polarity due to polymer-polymer or polymer-solvent interactions. Rheological characterization was undertaken to study the viscoelastic properties of the dispersed systems. Finally, two types of experiments to evaluate the polymer abilities as surfactant have been carried out. Firstly, the amphiphilic characteristics of this material allowed the incorporation of small amounts of an organic solvent in water forming only one phase, as well as the incorporation of small amounts of water in the organic solvent forming an emulsified phase. Then, the amphiphilic properties of this macrosurfactant have been fully exploited in order to form highly stable dispersions of carbon nanotubes in water.
\end{abstract}

(c) 2016 Elsevier Ltd. All rights reserved.

\section{Introduction}

Emulsions are mixtures of immiscible liquids in which one of them is finely dispersed within the continuous phase of the other [1]. Emulsified systems (generally dispersion of an oily/hydrophobic phase in water) play a key role in many production processes in industries [2-4]. The most effective strategy to inhibit the phase separation is through the addition of surfactants. These entities modify the interfacial characteristics of the dispersed phases and prevent from the coalescence of the system [5]. In the last years, the use of Pickering emulsions introduced an alternative to classical emulsions. In Pickering

\footnotetext{
* Corresponding author.

E-mail address: jmgiussi@quimica.unlp.edu.ar (J.M. Giussi).
} 
emulsions, particles act as stabilizers because these are partially wet by both liquids, oil and water. The particles are localized in the interface, thus providing a barrier to droplet coalescence [6]. For classical emulsions, it is well known that the incorporation of these amphiphilic molecules promotes the formation of a viscoelastic film around the dispersed system, thus decreasing the tendency to coalesce. While the use of conventional low molecular weight surfactants can, in first instance, promote the dispersion of oil phases in aqueous systems, colloidal stability of these systems is very limited, and sometimes a considerable amounts of surfactant is required to modify the interfacial properties of the disperse phases [7]. The surfactant abilities of these materials are not only useful for systems consisting of two immiscible liquids, but also for systems consisting of a liquid and a solid (i.e. carbon nanotubes and water). In this sense, the ability to disperse carbon nanotubes in water using amphiphilic polymer materials has allowed the development of nanotechnology in aqueous systems [8].

An important weakness of traditional surfactants compared to polymeric materials is a significant deterioration of their rheological characteristics at elevated temperatures. To overcome this disadvantage, some authors have proposed to combine the useful properties of polymeric materials with those of traditional surfactants [9-12]. While the rheological properties of polymer/surfactant systems have been extensively studied to date, most of the investigations concerned to low surfactant concentrations and their stability remain limited [13-15].

On the other hand, the implementation of amphiphilic block copolymers as emulsifying agents has shown to have higher efficiency than that of low molecular weight surfactants [16-19]. These systems are commonly called "polymeric surfactants". Compared to traditional surfactants, the polymeric surfactants have lower critical micelle concentrations and lower diffusion coefficients. The reduced mobility of polymeric surfactant is an important aspect since a high mobility of the emulsifier could weaken the formation of the stabilizing layer in the dispersed system. In this case, the hydrophilic layer provides steric stabilization and improvement of the colloidal stability of the emulsion in the presence of shear, stirring, or even sudden changes in ionic strength or temperature.

Thermal radical polymerization represents a widely used technique to produce polymeric materials at large industrial scale. This technique has some limitations in terms of the variety of monomers that can be employed as well as the polymeric structures that can be obtained. In addition, the production of block copolymers by this approach is limited and gaining control over the polymer properties at high conversions is not trivial [20].

Several authors have published articles on the preparation of amphiphilic copolymers using thermal radical polymerization. These works consist on the use of monomers with long polar and nonpolar pendant groups to confer amphiphilic characteristics to the macromolecular [21-25].

The aim of this study is to design and prepare a macrosurfactant displaying emulsifying properties using lauryl methacrylate and poly (ethylene glycol) methyl ether methacrylate as constituting monomer units. We studied the thermal properties of the copolymer obtained, its amphiphilic characteristics responsible for the emulsifying properties and its ability to disperse and stabilize carbon nanotubes in aqueous solutions.

\section{Experimental}

\subsection{Materials}

Lauryl methacrylate (LMA, 96\% Aldrich) and poly(ethylene glycol) methyl ether methacrylate (PEGMA, average Mn 500 Aldrich) were distilled under reduced pressure before use. The initiator, 1,1'-azobis(cyclohexanecarbonitrile) (VAZO, 98\%, Aldrich) and all solvents (diethyl ether (RPE, Anedra), toluene (RPE, Anedra), isopropanol (RPE, Anedra), chloroform (RPE, Carlo Erba) and tetrahydrofuran (RPE, Carlo Erba)) were used as received.

\subsection{Copolymer polymerization}

The copolymer was synthesized by solution radical polymerization using 1,1'-azobis (cyclohexanecarbonitrile) as a radical initiator, as previously reported [26]. Briefly, $4.00 \mathrm{~g}(8 \mathrm{mmol})$ of PEGMA and $0.51 \mathrm{~g} \mathrm{(2} \mathrm{mmol})$ of LMA were introduced into a Schlenk tube with a pre-weighed amount of initiator $(244 \mathrm{mg}, 1 \mathrm{mmol})$ and $3 \mathrm{~mL}$ of toluene. The mixture was protected from light and purged with $\mathrm{N}_{2}$ at $-10^{\circ} \mathrm{C}$ for $30 \mathrm{~min}$. Then, the closed tube was heated at $70{ }^{\circ} \mathrm{C}$. After $40 \mathrm{~min}$, the polymer was precipitated in diethyl ether and purified by two steps of dissolutions in chloroform and precipitation in diethyl ether, centrifuged and dried under vacuum. Yield was $26 \%$.

The poly-LMA and poly-PEGMA homopolymers were also prepared (see Supporting Information for details).

\subsection{Characterization techniques}

The ${ }^{1} \mathrm{H}$ NMR spectra of the polymers were recorded on a Bruker Spectrometer, $300 \mathrm{MHz}$. The typical spectral conditions were as follows: spectral width $3201 \mathrm{~Hz}$, acquisition time $4.09 \mathrm{~s}$ and 8-16 scans per spectrum. The digital resolution was $0.39 \mathrm{~Hz}$ per point. Chloroform- $\mathrm{d}_{1}$ was the solvent and tetramethylsilane (TMS) the internal standard. The sample concentration was $7.0 \mathrm{wt} . \%$ and the spectra were recorded at $40{ }^{\circ} \mathrm{C}$. 
The attenuated total reflection-Fourier transform infrared (ATR-FTIR) spectra of the polymer films were recorded on a Varian 660 FTIR spectrometer between 4000 and $400 \mathrm{~cm}^{-1}$ with a resolution of $2 \mathrm{~cm}^{-1}$ and 64 accumulated scans. The films were prepared by the solvent casting method in chloroform.

The average molecular weight and the molecular weight distribution were determined by SEC in a LKB-2249 instrument at $25^{\circ} \mathrm{C}$. A series of four $\mu$-Styragel columns $\left(10^{5}, 10^{4}, 10^{3}, 100 \AA\right.$ pore size) were used with chloroform as eluent. The polymer concentrations were $5 \mathrm{mg} / \mathrm{mL}$, and the flow rate was $0.5 \mathrm{~mL} / \mathrm{min}$. The polymer was detected by infrared (IR) absorption at $5.75 \mu \mathrm{m}$ with a Miram IA spectrophotometer detector. Poly methyl methacrylate standards supplied by Polymer Laboratories and Polysciences Inc. were used for calibration.

The copolymer and homopolymers thermal properties were evaluated by differential scanning calorimetry (DSC) and thermogravimetric analysis (TGA). Experiments were carried out in a DSC 8500 Hyper DSC Perkin Elmer, in nitrogen atmosphere, at $10{ }^{\circ} \mathrm{C} / \mathrm{min}$ heating and cooling rate, from -70 to $185^{\circ} \mathrm{C}$. TGA experiments were performed using a Q500-TA Instruments setup, under nitrogen, from room temperature up to $700{ }^{\circ} \mathrm{C}$ and gas purged at $90 \mathrm{~mL} / \mathrm{min}$.

The emulsifying properties were evaluated by dynamic light scattering (DLS) (Zetasizer Nano Z). To determine the scattering intensity of the copolymer dispersion as a function of solvent content, different solutions were probed at a wavelength of $632 \mathrm{~nm}$. The analysis of DLS and size results has been carried out through distribution fit. The viscosities values used were the solvent pure values at the measurement temperature $\left(20^{\circ} \mathrm{C}\right)$.

Rheological studies of $\mathrm{LMA}_{0.2}$-Co-PEGMA 0.8 copolymer solutions in chloroform (10 wt\%) were performed in a TA Instruments ARG2 Rheometer using the $60 \mathrm{~mm}$ parallel plate shear mode. Stepped flow and viscosity curves were determined at $5{ }^{\circ} \mathrm{C}$. Dynamic viscoelastic experiments were also performed to measure the storage modulus, $\mathrm{G}^{\prime}$, the loss modulus $\mathrm{G}^{\prime \prime}$, and the loss tangent, $\tan \delta$. The linear viscoelastic region was determined with the aid of a strain sweep. Frequency sweeps extending from 0.1 to $100 \mathrm{~Hz}$ were performed at $10^{\circ} \mathrm{C}$ and strain amplitudes of 1,100 and $500 \%$.

\section{Results and discussion}

\subsection{Copolymer synthesis and characterization}

The radical copolymerization of lauryl methacrylate (LMA) with poly(ethylene glycol) methyl ether methacrylate (average Mn 500) (PEGMA) led to a copolymer (LMA L $_{2}$-Co-PEGMA ${ }_{0.8}$ ) whose structure, ${ }^{1} \mathrm{H}$ NMR spectrum (in deuterated chloroform) and assignments of resonance signals are shown in Fig. 1c. Figs. 1a and $1 \mathrm{~b}$ show the ${ }^{1} \mathrm{H}$ NMR of poly-PEGMA and polyLMA homopolymers, respectively. The copolymer structure also was confirmed by ATR-FTIR: 2930 and $2850 \mathrm{~cm}^{-1}$ (C-H, Aliphatic), $1700-1730 \mathrm{~cm}^{-1}$ ( $\mathrm{C}=\mathrm{O}$, ester), 1050 and $1290 \mathrm{~cm}^{-1}$ (C-O, ester), $1180 \mathrm{~cm}^{-1}$ (C-O-C, ester of PEGMA).

The copolymer composition was estimated from the ${ }^{1} \mathrm{H}$ NMR spectrum (Fig. 1c) using the integral ratio of the peaks at $\delta=3.66 \mathrm{ppm}$ (signal $\mathrm{c}^{\prime}+\mathrm{d}^{\prime}$ for PEGMA monomer, see Fig. $1 \mathrm{a}$ ) and $\delta=1.29 \mathrm{ppm}$ (signal e for LMA monomer, see Fig. $1 \mathrm{~b}$ ), using Eq. (1), giving a value equal to monomer mole fraction in the initial mixture (feed), $\mathrm{LMA}_{0.2}-\mathrm{Co}_{-} \mathrm{PEGMA}_{0.8}$.

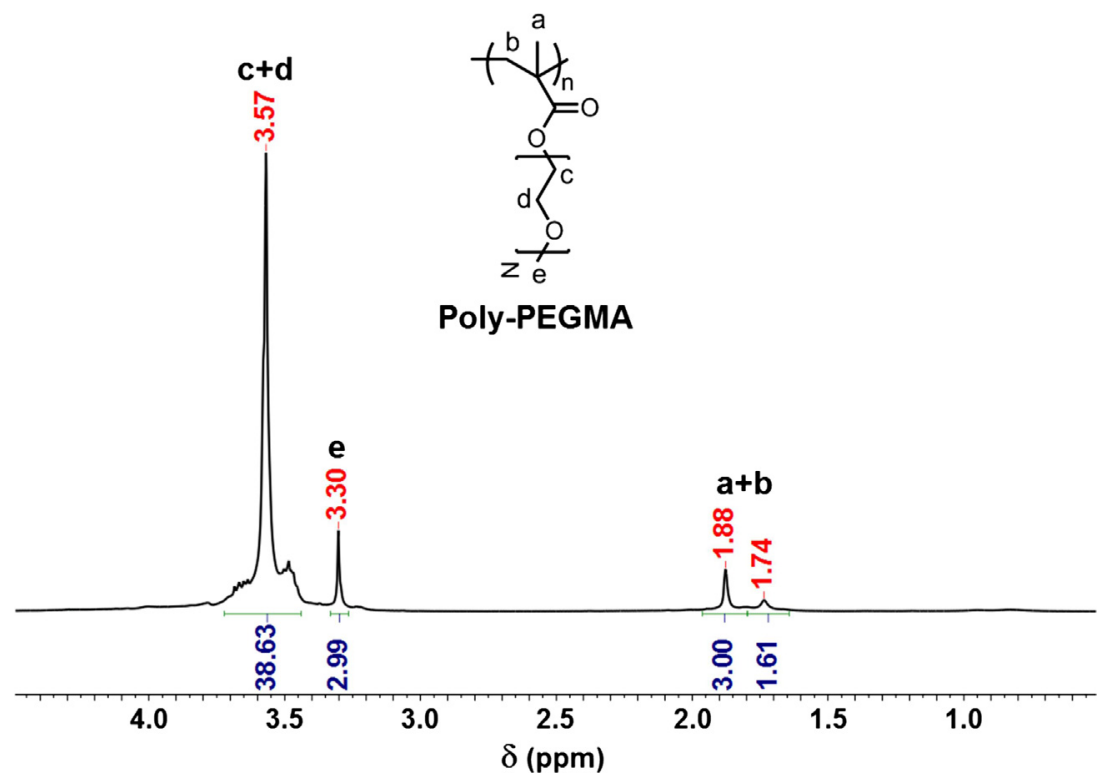

Fig. 1a. Structure of Poly-PEGMA and ${ }^{1} \mathrm{H}$ NMR spectrum with assignments of resonance signals. 


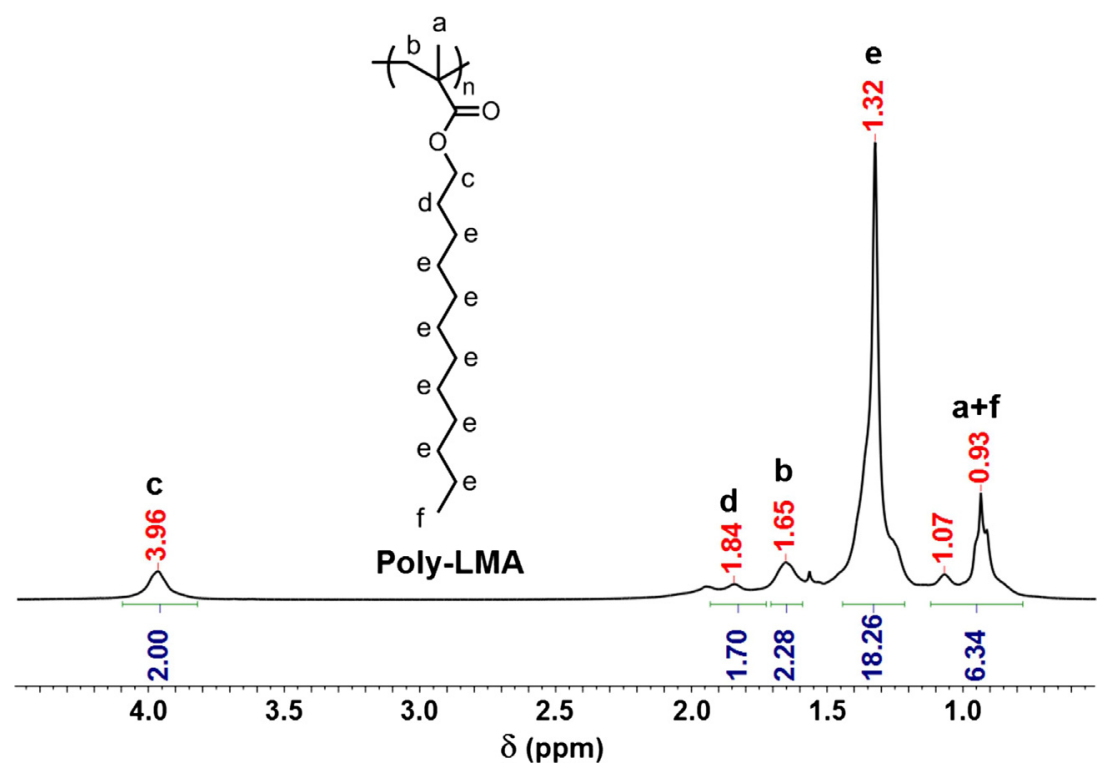

Fig. 1b. Structure of Poly-LMA and ${ }^{1} \mathrm{H}$ NMR spectrum with assignments of resonance signals.

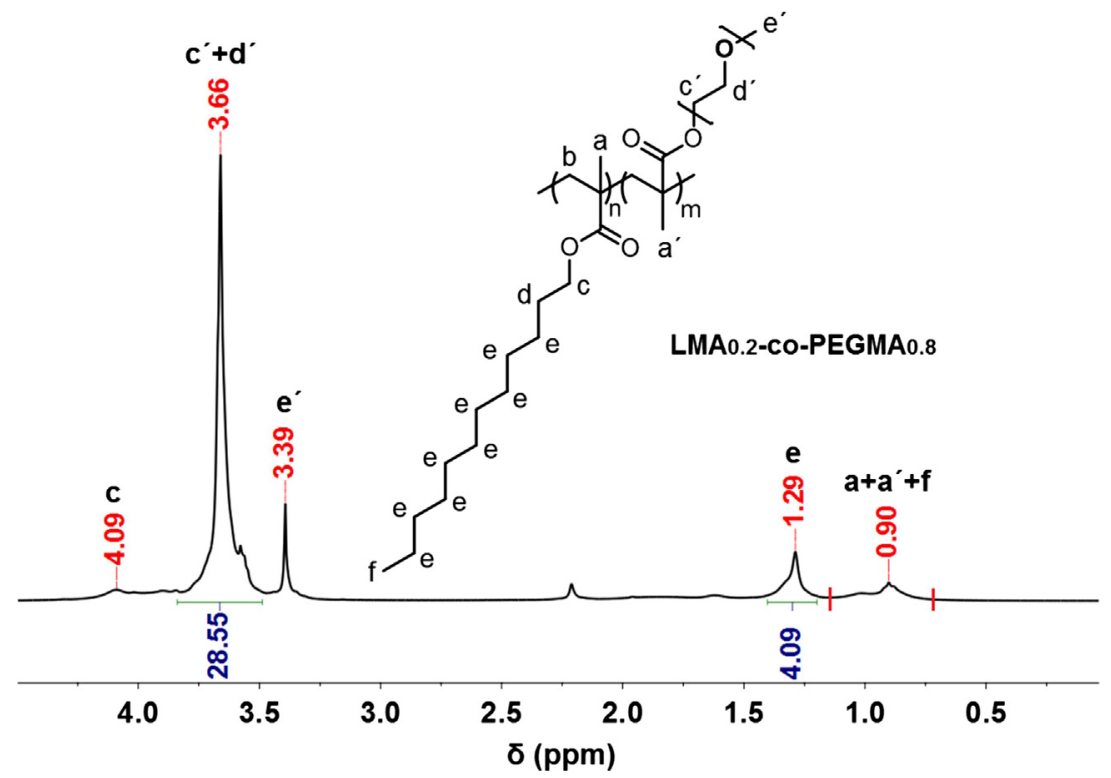

Fig. 1c. ${ }^{1} \mathrm{H}$ NMR spectrum with assignments of resonance signals $\left(\mathrm{LMA}_{0.2}-\mathrm{Co}-\mathrm{PEGMA} \mathrm{A}_{0.8}\right)$.

$$
F_{L M A}=\frac{I_{d=1.29} / 18}{I_{d=1.29} / 18+I_{d=3.68} / 38}
$$

$F_{L M A}$ represents the LMA molar fraction in the copolymers.

The $\mathrm{LMA}_{0.2}$-Co-PEGMA ${ }_{0.8}$ wt-average molecular weight $\left(M_{w}\right)$ was 275,500 and the polydispersity index (PDI) 1.6 . The PDI value suggest, based on theoretical predictions [27], that the disproportionation or chain transfer mechanisms are the predominant termination modes.

\subsection{Thermal properties}

DSC and TGA measurements provided information about thermal transitions and decomposition temperatures of the poly-PEGMA and poly-LMA homopolymers and $\mathrm{LMA}_{0.2}$-Co-PEGMA ${ }_{0.8}$ copolymer. Table 1 provides information about the 
Table 1

Thermal properties of DSC and TGA studies of copolymer and homopolymers synthesized. Glass-transition temperature (Tg), melting temperature (Tm), crystallization temperature (Tc), Initial degradation temperature (IDT), temperature of 5\% of degradation (T5\%) and Tmax. All values are represented in Celsius $\left({ }^{\circ} \mathrm{C}\right)$.

\begin{tabular}{llllll}
\hline Polymer & Tg & Tm & IDT & T max \\
\hline Poly-PEGMA & - & -3 & 245 & 287 \\
Poly-LMA & -48 & - & 199 & 243 \\
LMA $_{0.2}$-Co-PEGMA & -46 & 2 & 245 & 298 \\
\hline
\end{tabular}

thermal transition of copolymer and homopolymers synthesized. The Tg value of the poly-LMA is $-52{ }^{\circ} \mathrm{C}$, which is close to the literature values [28]. DSC curves for poly-PEGMA, showed a melting point at $-3{ }^{\circ} \mathrm{C}$ and $\mathrm{crystallization}$ point at $-48{ }^{\circ} \mathrm{C}$ the differences between these values might be ascribed to the metastability of crystalline segments formed between polyethylene oxide pendant groups in PEGMA monomer units [29]. LMA $_{0.2}$-Co-PEGMA ${ }_{0.8}$ showed both thermal transitions, therefore, these copolymer exhibit different structural configurations in the solid state: amorphous and semicrystalline. DSC curves are displayed in Supporting Information file.

TGA measurements of poly-LMA, LMA $_{0.2}$-Co-PEGMA ${ }_{0.8}$ and poly-PEGMA were performed under nitrogen stream to determine the decomposition temperatures for the synthesized polymers. Table 1 provides information about the thermal degradation of copolymer and homopolymers synthesized, initial degradation temperature (IDT), T 5\% and Tmax. Fig. 2 shows their decomposition profiles, these curves display only one thermal event and all characteristic temperatures shown in Table 2 show that $\mathrm{LMA}_{0.2}$-Co-PEGMA ${ }_{0.8}$ and poly-PEGMA exhibit higher thermal stability as compared to poly-LMA. These differences suggest a greater thermal stability of systems with higher content of the polar monomer, due to the presence of stronger interactions and complex radical degradation mechanism, as already reported for such systems [30]. On the other hand, the thermal degradation of poly(n-alkyl methacrylates) such as PMMA is essentially the reverse process of its polymerization, resulting in the monomer entities in $100 \%$ yield [31].

\subsection{Emulsification studies}

Because of their amphiphilic character, $\mathrm{LMA}_{0.2}$-Co-PEGMA ${ }_{0.8}$ has been dissolved in water, chloroform and toluene (only for this polymer composition, $\mathrm{LMA}_{0.2}$-Co-PEGMA ${ }_{0.8}$, the dissolution in all mentioned solvents was possible). Due to its macrosurfactant character, the copolymer is expected to self-organize in the selective solvents creating defined morphologies. In order to evaluate the emulsifying ability of the copolymer obtained, $\mathrm{LMA}_{0.2}$-Co-PEGMA $\mathrm{P}_{0.8}$ was dissolved (concentration $1 \mathrm{~g} \mathrm{~L}^{-1}$ ) in water, chloroform and toluene. The dynamic light scattering experiments were employed to determine the hydrodynamic diameters $\left(D_{H}\right)$ of possible micelles formed. The hydrodynamic diameter $\left(D_{h}\right)$ changed from $10.5 \mathrm{~nm}$ in toluene to $14 \mathrm{~nm}$ in chloroform and $20.5 \mathrm{~nm}$ in water (see supporting information for details). This behavior could be attributed to polymer-polymer or polymer-solvent interactions prevalent in solvents of different polarity, according to copolymer composition. The $D_{h}$ value confirms that the polymer particle is more expanded in water than in toluene. These results are consistent with the monomer composition of the copolymer. In water, the hydrophilic interaction of PEGMA monomer with the solvent prevails, producing a larger size, while the lower value obtained in toluene suggests possible PEGMA-PEGMA interactions and LMA-solvent interactions.

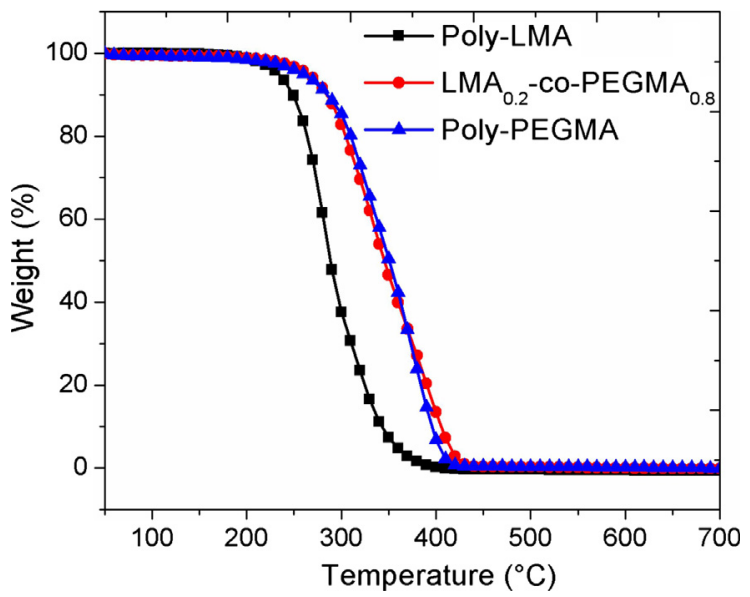

Fig. 2. TGA curves of Poly-LMA, $\mathrm{LMA}_{0.2}$-Co-PEGMA $\mathrm{A}_{0.8}$ and Poly-PEGMA under $\mathrm{N}_{2}$ at $10{ }^{\circ} \mathrm{C} / \mathrm{min}$. 
Table 2

DLS size in number for different polymer concentration and different amount of solvent dispersed (water and toluene) in the selected solvent (toluene and water, respectively).

\begin{tabular}{lll}
\hline Amount of dispersed solvent (\%) & Droplet sizes Toluene dispersed in water $(\mathrm{nm})$ & Droplet sizes Water dispersed in toluene $(\mathrm{nm})$ \\
\hline 0 & $21 \pm 7^{\mathrm{a}}$ & $11 \pm 5^{\mathrm{a}}$ \\
1 & $41 \pm 12$ & $41 \pm 5$ \\
5 & $63 \pm 13$ & $93 \pm 10$ \\
\hline
\end{tabular}

a Droplet size in absence of co-solvent.

In order to support the hypothesis that the copolymer may produce micellar structures in certain solvents, different rheological experiments have been carried out. The flow behavior of copolymer solutions were first studied through flow experiments. Fig. 3 shows the viscosity curve of a copolymer solution obtained at $5{ }^{\circ} \mathrm{C}$ in chloroform.

The shape of the curve is characteristic of a pseudoplastic liquid with some considerations: the first Newtonian plateau is not observed at low shear rates. Instead, a shear thinning is observed between shear rates of 0.01 and about $7 \mathrm{~s}^{-1}$. Then, an abrupt decrease of viscosity is found between 7 and $20 \mathrm{~s}^{-1}$ followed by a level off compatible with the second Newtonian plateau. The non-newtonian character of the solutions can be accounted for by some sort of aggregation/structuration of the copolymer in chloroform that can be destroyed with increasing shear rates. Also, a certain type of transition takes place at around $7 \mathrm{~s}^{-1}$, which entails a drop of the solution viscosity. As reported by Quintana et al. [32], this behavior may be related to two different processes: (i) the disruption of some kind of flocks that entails a diminution of their volume fraction, thus lowering the viscosity and (ii) at higher shear rates, coalescence is induced, increasing the aggregates size, which produces weaker interparticle interactions and therefore, decreasing the viscosity. To gain insight into this behavior, dynamic shear experiments were performed.

The viscoelastic properties of the copolymer solutions were determined through oscillatory testing. Amplitude strain sweeps at a frequency of $1 \mathrm{~Hz}$ were performed at two different temperatures 5 and $10{ }^{\circ} \mathrm{C}$ in chloroform and the results are depicted in Fig. 4.

Qualitatively, the behavior at both temperatures is the same, with absolute values of G' and G" being higher at lower temperature, as expected for this type of systems [33,34]. Analyzing the curve at $5{ }^{\circ} \mathrm{C}$, four different regions can be observed. In all the regions $G^{\prime}$ is lower than $G^{\prime \prime}$ pointing to a relatively liquid-like behavior. In region $1, G^{\prime}$ and $G^{\prime \prime}$ increase slightly with the strain amplitude. The rate of increment of $\mathrm{G}^{\prime}$ is higher than that of $\mathrm{G}^{\prime \prime}$, indicating that the system approaches to a solid-like behavior as the strain increases. This trend is clearer for the system at $10^{\circ} \mathrm{C}$ (see Fig. 3). The deformation applied to the solution may help the copolymer micelles to interact and reorganize into more ordered and stronger flocks. However, at a critical strain amplitude, both $G^{\prime}$ and $G^{\prime \prime}$ start to decrease with the strain amplitude (region 2 ). This fact can be associated with the disruption of the flocks as observed by flow experiments. This region leads to a linear viscoelastic region 3 where $\mathrm{G}^{\prime}$ and $\mathrm{G}^{\prime \prime}$ are almost independent of the strain amplitude and, finally, region 4 is attained at a critical stress where the non-linear viscoelastic region begins.

In Fig. 5, frequency sweep tests at $5{ }^{\circ} \mathrm{C}$ of the copolymer solutions in chloroform at strain amplitudes of 1,100 and $500 \%$ within regions 1,3 and 4, respectively are presented. The values of $G^{\prime}$ and $G^{\prime \prime}$ decrease from region 1 to region 4 as pointed out by the strain amplitude test. Moreover, a crossover of $G^{\prime}$ and $G^{\prime \prime}$ can be seen for the curves obtained at strain amplitudes within regions 1 and 3 but not for the case of strains within region 4 . The crossover frequency provides a good indication of the viscoelastic behavior of a solution. Solutions with lower crossover points have higher elastic contributions to their rheological properties [35]. The fact that curves obtained in region 1 have a crossover point lower than curves obtained in region

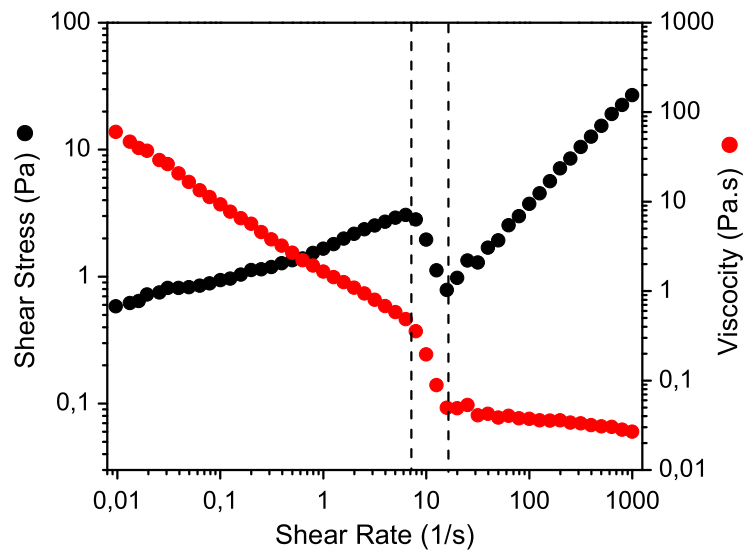

Fig. 3. Shear stress and shear viscosity as a function of shear rate under steady shear procedure. 


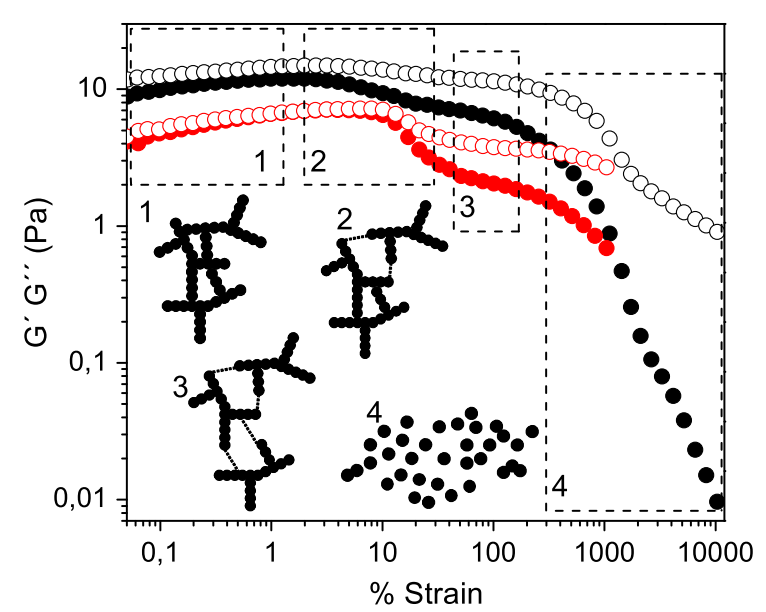

Fig. 4. Elastic (full symbols) and viscous modulus (open symbols) as a function of \% strain at $1 \mathrm{~Hz}$ of frequency of LMA ${ }_{0.2}$-co-PEGMA $\mathrm{A}_{0.8}$ at 5 (black) $10{ }^{\circ} \mathrm{C}$ (red). (1) clusters of micelles in the solution, (2) strain thinning (type I) due to the alignment of clusters with flow direction, (3) strong strain overshoot (type IV) due to the formation of larger clusters, (4) second strain thinning due to the break up or alignment with flow direction. (For interpretation of the references to colour in this figure legend, the reader is referred to the web version of this article.)

3 points to a higher elastic contribution in region 1 in accordance to the structural representation derived from the previous experiments. Also, there is no crossover point in the frequency range investigated in the region 4 as expected due to continuous loss of organization/structuring of the system at the highest strain amplitudes.

As the aim of this work was to obtain a copolymer with nonionic-macrosurfactants properties, to enhance the stability of oil/water interface, aqueous and organic solutions of $\mathrm{LMA}_{0.2}-\mathrm{Co}-\mathrm{PEGMA}_{0.8}$ were mixed with toluene and water, respectively. Small amounts ( 1 and $5 \%$ ) of water were added to a $\mathrm{LMA}_{0.2}-\mathrm{Co}-\mathrm{PEGMA}_{0.8}$ solution in toluene (concentration $1 \mathrm{~g} \mathrm{~L}^{-1}$ ), as well as small amounts ( 1 and $5 \%$ ) of toluene were added to $\mathrm{LMA}_{0.2}-\mathrm{Co}-\mathrm{PEGMA}_{0.8}$ aqueous solutions (concentration $1 \mathrm{~g} \mathrm{~L}^{-1}$ ). For toluene in $\mathrm{LMA}_{0.2}$-Co-PEGMA 0.8 aqueous solutions, one single phase was observed (Fig. $6 \mathrm{a}$ right). On the other hand, when water was added to $\mathrm{LMA}_{0.2}$-Co-PEGMA $\mathrm{A}_{0.8}$ toluene solutions, emulsified phases were observed (Fig. $6 \mathrm{a}$ left). The results presented show the ability of $\mathrm{LMA}_{0.2}-\mathrm{Co}-\mathrm{PEGMA}_{0.8}$ copolymer to incorporate both small amounts of organic solvent in water forming monodomain phases and small amounts of water in organic solvents forming emulsified phases. Similar results were obtained by Muñoz-Bonilla et al. [36] for block copolymers based on cyclohexyl methacrylate and di(ethylene glycol) methyl ether methacrylate.

Additionally, in order to evaluate the amphiphilic behavior of this copolymer and its dispersing capability, we tested the ability of $\mathrm{LMA}_{0.2}$-Co-PEGMA 0.8 to disperse multi-walled carbon nanotubes (CNTs) in water. The formation of suspensions by noncovalent stabilization of CNTs represents one of the most traditional strategies [37-40] to manipulate these nanomaterials and integrate them in different devices. The modification of CNTs by nonionic-macrosurfactants can be understood in
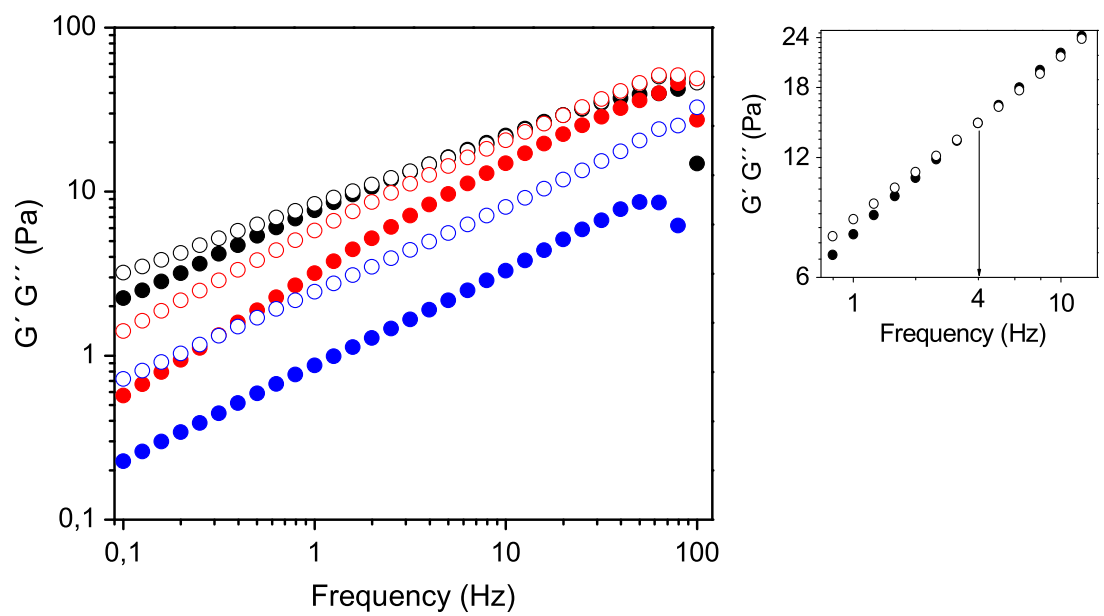

Fig. 5. Storage modulus (full symbols) and loss modulus (open symbols) as a function of frequency of LMA $\mathrm{A}_{0.2}$-co-PEGMA 0.8 at 1 (black), 100 (red) and 500 (blue) \% of strain. Inset: Crossover of modulus at $1 \%$ of strain. (For interpretation of the references to colour in this figure legend, the reader is referred to the web version of this article.) 

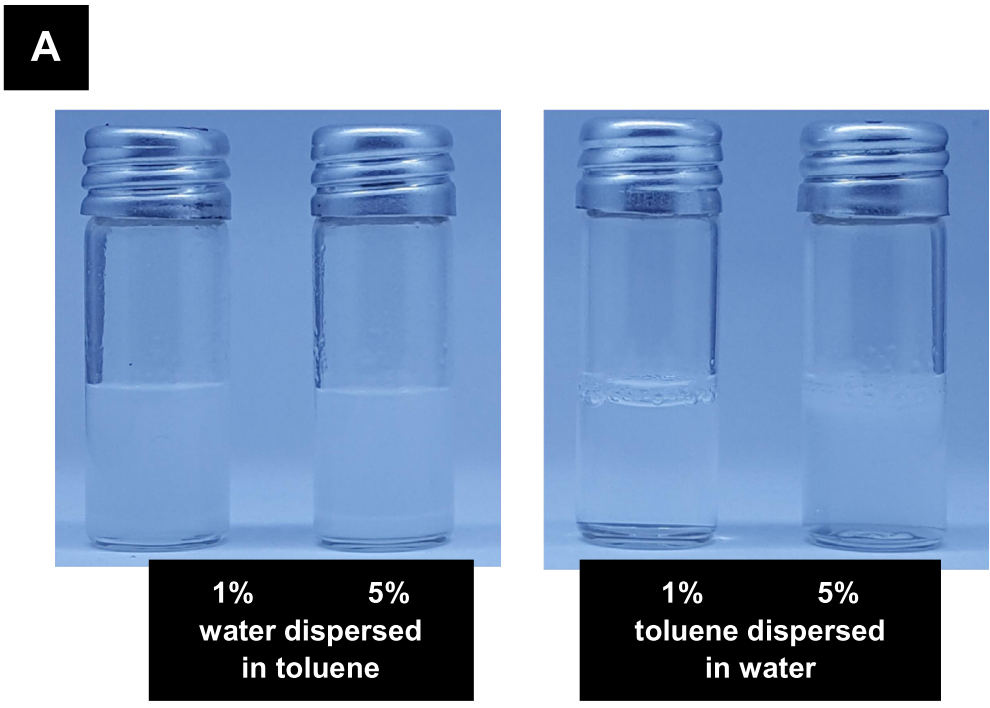

\section{B}
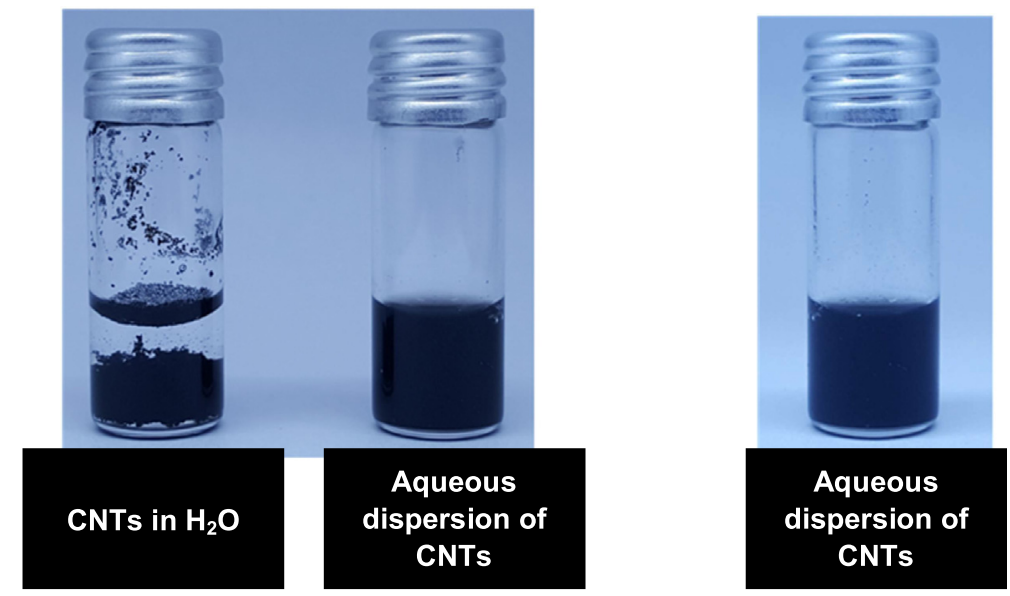

Fig. 6. (A) Aqueous and organic solutions of $\mathrm{LMA}_{0.2}$-co-PEGMA $\mathrm{A}_{0.8}$ (concentration $25 \mu \mathrm{g} / \mathrm{mL}$ ) with small amounts of toluene and water, respectively. 5 and $10 \%$ of water were added to a $\mathrm{LMA}_{0.2}$-co-PEGMA $\mathrm{A}_{0.8}$ in toluene solution (left), and 5 and $10 \%$ of toluene were added to $\mathrm{LMA}_{0.2}$-co-PEGMA $\mathrm{A}_{0.8}$ aqueous solutions (right). (B) Single-walled carbon nanotubes dispersions in a solution of $\mathrm{LMA}_{0.2}-\mathrm{Co}-\mathrm{PEGMA}_{0.8}$. The left-hand pictures correspond to CNTs in water and in aqueous $\mathrm{LMA}_{0.2}$-Co-PEGMA ${ }_{0.8}$ polymer solution. The right-hand image shows the dispersion of CNTs in aqueous LMA 0.2 -Co-PEGMA 0.8 polymer solution one week after dispersion.

terms of the steric stabilization conferred by the adsorbed polymer layer in which the hydrophobic segments of the surfactant makes contact with the CNTs, while its hydrophilic part is oriented towards the solution. In this context, a low concentration solution of $\mathrm{LMA}_{0.2}$-Co-PEGMA ${ }_{0.8}$ in water $\left(1 \mathrm{~g} \mathrm{~L}^{-1}\right)$ has allowed to disperse $1 \mathrm{mg} / \mathrm{mL}$ of CNTs. Fig. $6 \mathrm{~b}$ shows the impossibility of water to disperse CNTs (Fig. $6 \mathrm{~b}$ left). On the contrary, in the $\mathrm{LMA}_{0.2}$-Co-PEGMA - $_{\text {. }}$ aqueous solution the dispersion of CNTs was highly improved, thus leading to a very stable dispersion - after prolonged storage (weeks) the dispersion remained unchanged (Fig. 6b right).

In order to evaluate how the incorporation of small amount of solvent modify the size of micelles, Table 2 shows the DLS size, in number, obtained by distribution fit, for different polymer concentration and different amount of solvent dispersed (water and toluene) in the selected solvent (toluene and water, respectively).

As can be seen, small amounts of toluene modify the size of polymer micelles in water (second column and line 2 and 3 in Table 2) and vice versa, small amounts of water modify the size of polymer micelles in toluene (third column and line 2 and 3 in Table 2). The particle size increased with the addition of counter-solvent, due to their partial solubilization in the micelles. Interesting, the addition of $1 \%$ of solvent dispersed, give equal size by DLS, but the addition of $5 \%$ of solvent dispersed, the 
size increase is larger when dispersed water in toluene (column 3 in Table 2) than toluene in water (column 3 in Table 2). This behavior could be attributed to copolymer composition.

Comparing our results with the results obtained by Muñoz-Bonilla et al. [36], we can infer the properties of the copolymer presented in this work which was obtained by free radical polymerization in only one step using hydrophilic and hydrophobic monomers with large pendant groups, bear a close resemblance to a block copolymer obtained by living radical polymerization in more than one step using hydrophilic and hydrophobic monomers with short pendant groups. Both systems allow the homogeneous dispersion of two immiscible solvents and the micelles obtained have comparable size. The nature of the monomers in both cases is very similar, only that in our case these have large pendant groups and our polymer end up having the characteristics of a block system like the block polymers in the above-mentioned paper.

\section{Conclusions}

In summary, it has been demonstrated that radical polymerization is a good technique for the preparation of $\mathrm{LMA}_{0.2}$-CoPEGMA $_{0.8}$ copolymer. The molecular characteristics of the copolymer were determined by FTIR, NMR and SEC. Furthermore, the presence of two types of thermal transition in DSC indicates that this copolymer exhibit two types of morphologies in the solid state: amorphous and semicrystalline. Degradation of the polymers was found to take place within the range of 200$400{ }^{\circ} \mathrm{C}$, and greater thermal stability was observed for systems with higher content of the polar monomer, due to the presence of stronger interactions and complex radical degradation mechanisms. $\mathrm{LMA}_{0.2}$-co-PEGMA ${ }_{0.8}$ copolymer evidenced micelles formation in water, chloroform and toluene with hydrodynamic radii in the range of $10-20 \mathrm{~nm}$, as determined by DLS experiments. Rheological studies confirmed micelles presence due to complex behavior in the frequency sweep test, strain sweep tests and flow experiments. The obtained macrosurfactant allowed us to incorporate small amounts of organic solvent in water forming one-phase systems and to incorporate small amounts of water in organic solvents forming emulsified phases, showing the ability of copolymer-based micelles to incorporate a non-soluble solvent within their domains. Finally, due to the properties of this copolymer, a highly stable dispersion of carbon nanotubes in water was obtained.

\section{Acknowledgments}

The authors acknowledge financial support from ANPCyT (PICT 2010-2554, PICT-2013-0905, PICT 2015-0346), Fundación Petruzza, Consejo Nacional de Investigaciones Científicas y Técnicas (CONICET) (PIP 0370) and the Austrian Institute of Technology GmbH (AIT-CONICET Partner Lab: "Exploratory Research for Advanced Technologies in Supramolecular Materials Science" - Exp. 4947/11, Res. No. 3911, 28-12-2011). A.I. and G.D. gratefully acknowledge CONICET for a doctoral and postdoctoral fellowship, respectively. J.M.G and O.A. are CONICET fellows.

\section{Appendix A. Supplementary material}

Supplementary data associated with this article can be found, in the online version, at http://dx.doi.org/10.1016/j.eurpolymj.2016.12.027.

\section{References}

[1] P.A. Lovell, M.S. El-Aasser, Emulsion Polymerization and Emulsion Polymers, Wiley, New York, 1997.

[2] L.L. Schramm, Surfactants: Fundamentals and Applications in the Petroleum Industry, Cambridge University Press, Cambridge, 2000.

[3] J. Rubio, M.L. Souza, R.W. Smith, Miner. Eng. 15 (2002) 139-155.

[4] S. Xiu, A. Shahbazi, Renew. Sustain. Energy Rev. 16 (2012) 4406-4414.

[5] P.C. Hiemenz, R. Rajagopalan, Principles of Colloid and Surface Chemistry, Third Edition, Revised and Expanded; Undergraduate Chemistry: A Series of Textbooks, Taylor \& Francis, 1997.

[6] Y. Yang, Y. Ning, Z. Tong, C. Wang. Multiple Pickering Emulsions for Functional Materials, 2015.

[7] N.H. Raduan, T.S. Horozov, T.K. Georgiou, Soft Matter 6 (2010) 2321.

[8] S. Park, H. Yang, D. Kim, K. Jo, S. Jon, Chem. Commun. (Camb.) (2008) 2876-2878.

[9] E.D. Goddard, Colloids Surf. 19 (1986) 255-300.

[10] C. Methemitis, M. Morcellet, J. Sabbadin, J. Francois, Eur. Polym. J. 22 (1986) 619-627.

[11] J.C. Brackman, B. Jan, N. Engberts, J. Am. Chem. Soc. 112 (1990) 872-873.

[12] A.P. Mast, R.K. Prudhomme, J.E. Glass, Langmuir 8 (1993) 708-715.

[13] B. Magny, I. Iliopoulos, R. Zana, R. Audebert, Langmuir 10 (1994) 3180-3187.

[14] T. Annable, R. Buscall, R. Ettelaie, Langmuir 10 (1994) 1060-1070.

[15] H.M. Kopperud, F.K. Hansen, B. Nystrom, Macromol, Chem. Phys. 2394 (1998) 2385-2394.

[16] J.W. Anseth, A. Bialek, R.M. Hill, G.G. Fuller, Langmuir 19 (2003) 6349-6356.

[17] P.M. Claesson, R. Makuska, I. Varga, R. Meszaros, S. Titmuss, P. Linse, J.S. Pedersen, C. Stubenrauch, Adv. Colloid Interface Sci. 155 (2010) 50-57.

[18] P. Chambon, A. Chemtob, E. Cloutet, H. Cramail, S. Gibanel, Y. Gnanou, V. Héroguez, D. Quéméner, B. Radhakrishnan, Polym. Int. 55 (2006) $1146-1154$.

[19] Y. Sela, S. Magdassi, N. Garti, Colloid Polym. Sci. 272 (1994) 684-691.

[20] N.V. Tsarevsky, K. Matyjaszewski, Chem. Rev. 107 (2007) 2270-2299.

[21] J. Zhou, L. Wang, C. Wang, T. Chen, H. Yu, Q. Yang, Polymer 46 (2005) 11157-11164.

[22] L. Gargallo, A. Opazo, D. Radic, Eur. Polym. J. 26 (1990) 727-730.

[23] A. Leiva, L. Gargallo, D.J. Radic, Macromol. Sci. Part B 37 (1998) 45-57.

[24] H. Ahmad, M.K. Hasan, M.A.J. Miah, A.M.I. Ali, K. Tauer, Polymer 52 (2011) 3925-3932.

[25] A. Matsumoto, N. Murakami, H. Aota, J. Ikeda, I. Capek, Polymer 40 (1999) 5687-5690.

[26] J.M. Giussi, P.E. Allegretti, M.S.J. Cortizo, Polym. Sci. Part A, Polym. Chem. 50 (2012) 4161-4169. 
[27] G. Odian, Principles of Polymerization, McGraw-Hill Inc, New York, 2004.

[28] S. Rogers, L. Mandelkern, J. Phys. Chem. 61 (1957) 985-991.

[29] R.V. Castillo, M.L. Arnal, A.J. Müller, I.W. Hamley, V. Castelletto, H. Schmalz, V. Abetz, Macromolecules 41 (2008) 879-889.

[30] L.-P. Blanchard, V. Hornof, L. Hong-Ha, S.L. Malhotra, Eur. Polym. J. 10 (1974) 1057-1067.

[31] F. Bertini, G. Audisio, V.V. Zuev, Polym. Degrad. Stab. 89 (2005) 233-239.

[32] J.M. Quintana, A.N. Califano, N.E. Zaritzky, P. Partal, Food Sci. Technol. Int. 8 (2002) 213-221.

[33] K. Hyun, S.H. Kim, K.H. Ahn, S.J.J. Lee, Nonnewton. Fluid Mech. 107 (2002) 51-65.

[34] K. Hyun, M. Wilhelm, C.O. Klein, K.S. Cho, J.G. Nam, K.H. Ahn, S.J. Lee, R.H. Ewoldt, G.H. McKinley, Prog. Polym. Sci. 36 (2011) $1697-1753$.

[35] H.Y. Lin, J.C. Tsai, L.S. Lai, Food Hydrocoll. 23 (2009) 2331-2338.

[36] A. Muñoz-Bonilla, M. Fernández-García, M.L. Cerrada, G. Mantovani, D.M. Haddleton, Eur. Polym. J. 43 (2007) 4583-4592.

[37] A. Setaro, C.S. Popeney, B. Trappmann, V. Datsyuk, R. Haag, S. Reich, Chem. Phys. Lett. 493 (2010) 147-150.

[38] M. Sheikholeslam, M. Pritzker, P. Chen, Langmuir 28 (2012) 12550-12556.

[39] Z. Wang, Q. Liu, H. Zhu, H. Liu, Y. Chen, M. Yang, Carbon N. Y. 45 (2007) 285-292.

[40] Y. Ji, Y.Y. Huang, A.R. Tajbakhsh, E.M. Terentjev, Langmuir 25 (2009) 12325-12331. 